\title{
How do we know who to include in collaborative research? Toward a method for the identification of experts
}

\author{
Matthias Otto Müller ${ }^{\mathrm{a}, \mathrm{b}, *}$, Stefan N. Groesser ${ }^{\mathrm{a}, \mathrm{c}}$, Silvia Ulli-Beer ${ }^{\mathrm{a}, \mathrm{b}}$ \\ ${ }^{a}$ Interdisciplinary Centre for General Ecology (IKAÖ), University of Bern, Schanzeneckstr. 1, Postfach 8573, 3001 Bern, Switzerland ${ }^{1}$ \\ ${ }^{\mathrm{b}}$ Paul Scherer Institut, Dynamics of Innovative Systems, 5232 Villigen PSI, Switzerland ${ }^{2}$ \\ ${ }^{\mathrm{c}}$ Institute of Management (IfB), University of St. Gallen, Dufourstrasse 40a, 9000 St. Gallen, Switzerland ${ }^{3}$
}

\section{A R T I C L E I N F O}

\section{Article history:}

Received 26 January 2007

Accepted 7 July 2011

Available online $\mathrm{xxxx}$

\section{Keywords:}

Stakeholder analysis

Actor analysis

OR in societal problem analysis

Problem structuring methods

System Dynamics

Collaborative research

\begin{abstract}
A B S T R A C T
Collaborative research, defined as research involving actors participating in the problem situation under study, has an important role in operational research, strategic management and systems thinking. In a recent study, we found that a strong organizational focus incorporated into many soft operational research (OR) approaches is inadequate for studying societal problem situations, which are fragmented and have no clear boundary. Specifically, we failed to find a process of identifying individuals that is capable of representing the perspectives of actors and sufficient for research into societal problem situations. We found no clear terminology accounting for ontological differences between actors, individuals representing them and conceptual representations of acting entities. In response to this gap in the literature, we propose terminology that differentiates among actors (individuals or collective entities in the real world), experts (individuals capable of representing the perspective of an actor) and agents (ideal-typical representations of actors). Based on this terminology, we propose an iterative method to guide the assembly of an expert group to undertake collaborative research into societal problem situations. To demonstrate the application of our method, we present selected insights from our study in an electronic supplement.
\end{abstract}

(c) 2011 Elsevier B.V. All rights reserved.

\section{Introduction}

Practitioners and scholars in strategic management and public policy frequently deal with pluralistic problem situations characterized by high degrees of uncertainty and complexity (Schwaninger, 2009). Spanning a range of paradigms, the intersecting fields of strategic management, operational research and systems thinking have developed an array of approaches that are helpful in such situations (Hermans and Thissen, 2009; Rosenhead and Mingers, 2001).

By involving the participants of a problem situation in a collaborative process, better insights can be gained for determining policy and strategy because knowledge beyond the boundaries of an organization or a policy-making circle becomes available. Hence, a broader and more systematic understanding of the problem situ-

\footnotetext{
* Corresponding author at: Interdisciplinary Centre for General Ecology (IKAÖ), University of Bern, Schanzeneckstr. 1, Postfach 8573, 3001 Bern, Switzerland. Tel.: +41 (0)31631 3940; fax: +41 (0)316318733.

E-mail addresses: matthias.mueller@ikaoe.unibe.ch, email.von.matthias.mueller@gmail.com (M.O. Müller)

${ }^{1}$ www.ikaoe.unibe.ch.

2 http://dis.web.psi.ch/

${ }^{3}$ www.ifb.unisg.ch.
}

ation can be achieved, which, in turn, allows the development of more effective strategies and policies.

Collaborative research refers to research involving participants of the situation under study as partners in a process of mutual learning. The emphasis is on initiating and participating in the collective co-production of knowledge (Pohl, 2008, p. 52). This is in contrast to research that treats participants as objects of inquiry, such as conventional interviews and survey research or experiments. Collaborative research shares basic assumptions with research approaches that are participatory, transdisciplinary and interactive (Robinson and Tansey, 2006; Scholz et al., 2000; Thompson Klein et al., 2001; Wiek, 2007; Wiek and Walter, 2008 ), and in terms of practice, it resembles action research as described by Reason and Bradbury (2001).

In a recent study, we applied collaborative methods and concepts from strategic management, operational research and systems thinking to investigate how the diffusion of energy-efficient construction practices across different categories of actors could be accelerated to contribute to making Switzerland's stock of new buildings more sustainable. We initially relied on stakeholder theory (Freeman, 1984; Mitchell et al., 1997; Eden and Ackermann, 1998), cognitive mapping (Ackermann and Eden, 2001) and System Dynamics group model building (Vennix, 1996; Andersen and Richardson, 1997; Andersen et al., 1997) as our set of methods.

0377-2217/\$ - see front matter (C) 2011 Elsevier B.V. All rights reserved. doi:10.1016/j.ejor.2011.07.014 
In the wake of our study, we realized that the context in which we applied our set of methods differed problematically from the context where these methods emerged and are generally applied.

In particular, studies often lack a clear distinction between organizational perspectives (e.g., What constitutes a problem situation for organization X?) and inter-organizational (societal) perspectives (e.g., How is a societal problem situation brought about by the interactions of several actors?). We had investigated a situation involving several organizations and their environment rather then applying our set of methods from within an organization. We characterize this setting as a societal problem situation rather than an organizational problem situation (see Section 3.1). Collaborative research is highly appropriate in societal problem situations because the initial uncertainties are generally larger when compared to an organizational context and, hence, must be compensated by accessing the knowledge of the situation's participants. However, the question of who to collaborate with is also more difficult when compared to research from a predominantly organizational perspective, as it is much less clear what kind of actors are important to understand the situation and who can adequately represent the perspective of important actors.

For guidance on how to identify individuals capable of adequately representing the carriers of agency in the societal problem situation under study, we turned to the literature on strategic management, operational research and systems thinking. We found that there does not appear to be a clear distinction between real, acting entities and abstract categories referring to such entities. Individual persons and collectives of individual persons, such as organizations, are real entities. Abstract categories, such as "consumers," "regulators" or "architects" can neither directly act nor collaborate in research projects. For stakeholder analysis from an organizational perspective, it may be unproblematic to ignore this difference; however, in the context of collaborative research into societal problem situations, this difference is crucial, as the purpose of collaboration is to enlarge the epistemic base by using real persons (experts) to represent the perspectives of abstract categories of actors. In response to this gap in the literature, we propose terminology that differentiates between actors (individuals or collective entities in the real world), experts (individuals capable of representing the perspective of an actor) and agents (ideal-typical representations of actors).

In line with the lack of clear distinction between real, acting entities and their abstract categories, we found that the contributions in the literature addressing the identification of acting entities in problem situations did not satisfy our specific requirements (see Section 2 ). We address this gap by proposing an iterative process that develops the understanding of the societal problem situation and its important actors so that individuals capable of representing them can be identified. In collaboration with these experts, models or conceptualizations of agency in the societal problem situation can be developed, which, in turn, contribute to an enhanced understanding of the societal problem situation.

Summarizing the discussion above, this article addresses the following three research questions:

1. How should inter-organizational and fragmented research settings, in contrast to organizational settings, be conceptualized in view of collaborative approaches in strategic management, operational research and systems thinking?

2. How should differences in the ontological status of carriers of agency in problem situations be conceptualized in a consistent terminology?

3. How can individuals capable of representing the perspective of important actors in societal problem situations be identified methodologically?
By addressing these questions, we contribute to collaborative research methodology in strategic management, (soft) OR and System Dynamics. In addition, we hope to stimulate further research and initiate a broader discussion.

The article is organized as follows. In Section 2, we review the literature and substantiate the research gap we address. Section 3 outlines the theoretical foundations, particularly our terminology of acting entities and our conceptualization of societal problem situations. Section 4 presents the method we built based on these theoretical foundations. In Section 5, we summarize our insights, reflect on the merits of our method as a plug-in for collaborative research and point out the need for further research. In addition, we describe the application of our method in an electronic supplement, by providing an illustrative case study based on our research project. Within that supplement, we derive a small set of propositions regarding what we expect other researchers to gain from applying the method.

\section{Literature review}

In the following, we review the literature on stakeholder theory, System Dynamics and problem structuring methods.

\subsection{Stakeholder theory}

Freeman (1984) popularized the stakeholder approach in strategic management. He defined stakeholders as "any group or individual who can affect or is affected by the achievement of the organization's objectives" (Freeman 1984:46). Since the introduction of the concept, a broad, extensive and heterogeneous body of literature has emerged. Following the popularity of the concept and its use in various contexts, several different definitions of stakeholders have been used (Friedman and Miles, 2006:3,5-8). Some definitions have moved far away from Freeman's original definition. For example, in systems thinking, the term "stakeholders in a system" (Ackoff, 1999:103) is sometimes used to refer to what we would define as actors in the system. In recent years, collaborative strategy-making approaches with a strong focus on collaborating with stakeholders have emerged (see, for example, Eden and Ackermann, 1998).

Stakeholder theory has developed a wide range of classifications and criteria to determine which actors should be considered stakeholders of a specific organization (e.g., Savage et al., 1991; Donaldson and Preston, 1995; Eden, 1996; Mitchell et al., 1997). However, these only provide guidance regarding what class, category or type of stakeholder should be considered important. Achterkamp and Vos (2007) found that the problem of who the stakeholders are and which stakeholders ought to be addressed remains unresolved. In particular, they hold that the "categorization schemes as such are insufficient for actually identifying stakeholders in a specific case" (2007:6).

Bryson (2004) presents 15 stakeholder identification and analysis techniques grouped around four basic categories. These are (1) organizing participation; (2) creating ideas for strategic interventions; (3) building a winning coalition around proposal development, review and adoption; and (4) implementing, monitoring and evaluating strategic interventions. Our method is as a contribution to the first phase, namely, organizing participation. Here, Bryson (2004) provides a detailed process regarding how to choose participants in stakeholder analysis. His process consists of the following five major steps. To prepare the process, a small group first conducts preliminary stakeholder analysis. Based on these insights, a larger group of stakeholders is assembled in the second step to carry out further analysis, such as the identification of stakeholders to be involved in the change effort. In the third step, the stakeholder group 
is asked who should be included in further meetings. Then, the full group of involved stakeholders is complete, and stakeholder analysis techniques can be used with the full group as the fourth step. In the fifth step, the different roles (e.g., sponsors, champions, coordinating group, planning team and advisory group) in the change effort are distributed to stakeholders. In addition to this process, Bryson (2004) provides a participation planning matrix, which allows the planning of different degrees of stakeholder involvement, ranging from informing to empowering.

Other than an approach limited to stakeholder identification for projects in organizations (Achterkamp and Vos, 2007), we know of only one further contribution from stakeholder theory dealing with the identification of experts beyond the provision of classification schemes. Eden (1996) describes an approach to conceptualize and identify stakeholders in a project with the Northern Ireland Prison Service. In this project, societal actors are considered according to the degree to which they influence the organization. Based on the power-interest diagram, stakeholders are classified into the following groups: players, crowd and leaders/context setters. Eden (1996:48) uses the term "actors" to refer to "those who have the power to act in a way which has an impact on the future of the strategy-making organization" (players and leaders/context setters). However, he goes beyond classification schemes. In his approach, collaborator workshops with stakeholders are employed to enrich the strategy-making process with insights from outside the organization.

We find that our research question 1 cannot be answered based on the literature on stakeholder theory. Regarding research question 3, we find that some contributions have addressed the issue of how to identify individuals capable of representing important stakeholders in collaborative research. However, the literature does not provide a rigorous method for selecting such individuals in societal problem situations.

\subsection{System Dynamics}

In a strand of research in the field of System Dynamics called group model building (Andersen et al., 1997; Andersen and Richardson, 1997; Vennix, 1996), the benefit of working with representatives of the system under study is well recognized. Vennix (1996), for example, outlines several guidelines for selecting who to involve in the model-building sessions. Including "those present who have the power to act, i.e., those who can implement a decision" (111) is an important point if the goal of the project is to bring about particular decisions. Regarding the size of the expert group, Vennix (1996, 111pp.) finds that there are trade-offs between small and large and between homogenous and heterogeneous groups ${ }^{4}$ : in a large group, the organizational platform for change and the commitment to a decision is often rather large, but the satisfaction and participation of group members may be low. In diverse groups, the quality of the model may be high, but diversity may result in tensions that undermine the group's performance.

Although research question 1 is not explicitly answered in the System Dynamics literature, modeling dynamic complexity over large societal settings is standard practice in System Dynamics. Regarding research question 2 , we did not encounter any terminology that clearly considers the different ontological status of experts, actors and agents. Regarding research question 3, we did not find a rigorous method to guide the identification of "those (...) who have the power to act" or "who can implement a decision" in the System Dynamics group model building literature. We conclude that the System Dynamics group model building

\footnotetext{
${ }^{4}$ See Vennix (1996:111pp.) for a richer account, including empirical research into the effect of group composition on performance. Vennix (1999) provides further
} grounding on group model building. literature treats the process of identifying representative actors in the system under study rather superficially, particularly when compared to our method.

\subsection{Problem structuring methods}

Mingers and Rosenhead (2004:531) argue that unstructured problems are characterized by multiple actors, multiple perspectives, incommensurable and/or conflicting interests, important intangibles and key uncertainties. In response, problem structuring methods have become widely accepted as a "significant new direction for operational research and the systems movement" (Rosenhead, 2001a:xiii). These methods structure issues, problems and decision situations rather than solve them. In practice, a large number of methods are applied to address such problems, and, quite frequently, methodologies are pragmatically combined (Mingers and Rosenhead, 2004).

However, in a contribution reflecting the use of problem structuring methods in multi-organizational teams, Franco (2009:194) argues that "most of what has been reported about PSMs [Problem Structuring Methods, the authors] in the OR literature has focused on management teams operating within single organizations". This statement complies with our finding regarding research question 1 that problem structuring methods generally do not account for the inter-organizational settings we call societal problem situations. The notable exception in the context of problem structuring methods is Soft Systems Methodology (SSM) (Checkland and Scholes, 1990; Checkland, 1993, 2001), which aspires to "guide action in trying to 'manage' (in a broad sense) real-world problem situations" (Checkland and Scholes, 1990:5). Here, tools such as rich pictures (Checkland and Scholes, 1990:5) naturally promote a systemic perspective on problem situations that goes beyond a focus on single organizations.

Regarding research question 2, we find that several problem structuring methods provide terminologies to address different actors yet fail to clearly account for the difference between abstract entities, individuals representing them and models employed to represent agency. SSM has a terminology for categorizing different actors, namely clients, problem-owners and problem-solvers (Checkland and Scholes, 1990:47). Strategic options development and analysis (SODA) (Ackermann and Eden, 2001) aims to identify supporters or saboteurs of organizations' strategic intentions. The strategic choice approach (Friend, 1990) encompasses the team-like group, the partnership group, the inclusive group and, finally, the multi-organizational groups. We find that collaborating with a "multi-organizational team" is a variant of collaborative research, which is compatible with our conceptualization of collaborative research in societal problem situations. By including non-organizational actors, such as consumers or voters, our notion of collaborative research into societal problem situations carries this further.

Regarding research question 3, we find that no other contributions in the literature provide a method with a similar rigor to what we propose in Section 4. Neither robustness analysis (Rosenhead, 2001b), the strategic choice approach, drama theory and confrontation analysis (Bennet et al., 2001) nor the viable system methodology (Beer, 1984) profoundly address the issue of identifying individuals willing to represent actors in societal problem situations. SSM also does not include a method for doing so. Even Hermans and Thissen (2009), who provide an extensive evaluation of actor analysis methods from soft OR methods in the public policy context, do not address this practical topic.

\subsection{Conclusions from the literature review}

Summarizing the results of our literature review, we find that the notion of the societal problem situation is not alien to 
stakeholder theory, System Dynamics and problem structuring methods. Rather, the term "societal problem situation" is an extension of the literature, and it promises to facilitate the application of collaborative research methods in inter-organizational settings. Although several terminologies dealing with acting entities can be found in the literature, there is generally no clear distinction between actors, individuals representing them and models of agency. Our terminology provides clarity in this respect. Finally, the question of how to identify individuals capable of representing actors in collaborative research has been partially addressed. To meet the requirements of research into societal problem situations, the approaches found in the literature are somewhat unsatisfactory, as they seem to rely, to a substantial degree, on knowledge available from an organization. For research into societal problem situations, however, it might be initially unclear where the boundary of the situation lies, and it might not be evident where preliminary work should begin. The fragmented nature of societal problem situations makes it unlikely that there is one person who oversees all relevant actors.

These presented findings do not necessarily mean that the identification and selection of participants in collaborative research projects has, thus far, been systematically flawed. We merely maintain that no discussion of this initial phase of collaborative research has occurred in the literature. We can, however, speculate that the selection of experts in collaborative research projects addressing societal problem situations has often been ad hoc. Moreover, in most cases reported in the literature, the selection of participants in workshops is treated rather briefly. For example, White and Lee (2009:689) mention "invited people" as the persons invited to workshops for a project to make Bristol a sustainable city.

\section{Theoretical foundations}

In this section, we introduce the general actor terminology used in our method and specify the characteristics of societal problem situations.

\subsection{Conceptualizing acting entities}

To conceptualize acting entities, we propose the following distinctions between the terms actor, expert and agent. Actors are entities in the real word who carry out activities. They can either be individual persons or collectives of real persons, such as an organization or a social movement. Experts are always real, individuals capable of representing the perspective of actors or categories of actors in addition to their individual perspectives. For example, the manager of a trust fund may be able to serve as an expert representing the trust fund's role in a problem situation. Finally, agents are ideal-typical representations of actors or categories of actors.

Categories of actors are generally used to merge several actors sharing common characteristics. For example, "consumers" or "suppliers" are groups of actors who share particular characteristics. Agents, on the other hand, are the result of methodological efforts directed at developing scientifically sound and useful models of agency. In the terminology of SSM, agents are a feature of systems thinking about the real world. By methodologically manipulating and debating agents, researchers can derive insights to better understand the real world.

By developing a typology of agents, actors in the problem situation can be represented in models. Moreover, by giving the agents behavioral rules, it is possible to model the behavior of actors. This holds regardless of the methodology used or the specifics of the situation under study. Implementing a typology of agents, however, depends strongly on the theoretical framework used to approach the issue and the methodology used for modeling.

\subsection{Characteristics of societal problem situations}

Collaborative research is particularly useful when researchers or practitioners are confronted with situations in which the actions of several actors, each situated in his or her specific context, give rise to an issue that is identified as important and unpleasant by more than just a single actor.

The notion conveyed by the term "problem situation" is well established in the literature. For example, in the management literature, Ackoff (1979) sees problems as analytical abstractions from messes. Messes are "dynamic situations that consist of complex systems of changing problems that interact with each other". Ackoff regards problems as being open to solutions based on optimization, while messes require a more thoughtful management approach. Similarly, Checkland (1993:154) describes structured problems as problems that "can be explicitly stated in a language which implies that a theory concerning their solution is available". Unstructured problems are problems that are "manifest in a feeling of unease but which cannot be explicitly stated without this appearing to oversimplify the situation". Furthermore, Rittel and Webber (1973) differentiate between "wicked" and "tame" problems, and Schön (1987) uses the image of a swampy lowland rife with messy, confusing problems that defy technical solutions to address an idea similar to the term "problem situation".

Research on the sociology of social problems highlights the fact that the definition of a problem situation strongly depends on subjective interpretation. For example, Blumer (1971) rejects the view that social problems are primarily based on an objective condition with an objective makeup. Instead, social problems exist primarily in terms of how they are defined and conceived by society. Social problems are always a "focal point for the operation of divergent and conflicting interests, intentions and objectives" (Blumer, 1971:300). Focusing more closely on the process of constructing social problems, Kitsuse and Spector (1973:415) conceived of social problems as "the activities of groups making assertions of grievances and claims with respect to some putative condition". They argue that analysts of social problems should focus on the explanation of the "subjective elements" of social problems (418). To find a middle way, Weinberg (2009) cautions against focusing purely on the subjective element. Rather, he calls for a more balanced approach that considers the meaning and the causes of the claim-making process.

Synthesizing this discussion, we can characterize societal problem situations as highly fragmented situations, where it may not be clear what exactly the problem is, what kind of actors are involved in it, and who is responsible for addressing the problem. In particular, fragmentation means that actors in the problem situation may not be aware that they are participants in a societal problem situation. For example, consumers may have no awareness that they are part of the societal problem situation of "pesticide use and loss of biodiversity". In our opinion, collaborative research based on systems-thinking methodologies is best suited to address such situations. This is because collaborative research allows participants' to drawn upon their knowledge of the problem situation and because systems thinking methodologies integrate "objective" and "subjective" aspects of societal problem situations (Schwaninger, 2004).

Due to the fragmented nature of societal problem situations, the research methodology cannot rely on one single perspective to identify the important actors. Instead, identifying important actors and the experts representing them must be grounded in empirical research into the problem situation itself. The next section proposes a method for doing this. 


\section{Description of the method}

In this section, we describe how individuals who are capable of representing the perspective of important actors in societal problem situations can be identified methodologically.

\subsection{General description}

We divide the process of identifying experts into four phases, as shown in Fig. 1. First, an understanding of the problem situation must be developed (phase 1) to understand the important actors of the problem situation (phase 2). Then, for all actors preliminarily considered important, experts who represent the perspectives of important actors must be identified (phase 3). By working together with the experts, the actors and their behavioral rules are conceptualized as agents (phase 4). This knowledge and the model used to structure it further develop the understanding of the problem situation (again phase 1) and may prompt researchers to either include further actors or reconsider the value of actors previously seen as important (again phase 2).

Our approach is iterative and evolutionary and seems well suited to guide the initial phases of collaborative research into societal problem situations. It is evolutionary because, after each phase, we undertake empirical testing and, if needed, update the insights gained. The method is iterative because the individual steps should be undertaken several times. The two types of arrows in Fig. 1 visualize this process. Bold arrows signify increasing knowledge and confidence as a result of iterations, while the thin arrows stand for testing processes and updating this knowledge. By circling several times through the four stages, an understanding of the problem situation and its actors develops until researchers deem that their understanding is saturated. The practice of repeated checking and adapting until a saturated understanding is reached is similar to the hermeneutic circle (Gadamer, 1975; Schön, 1983) and qualitative research methods, such as grounded theory (Glaser and Strauss, 1967; Strübing, 2004; Flick, 2005).

Once researchers reach the conclusion that the important actors of the problem situation have been identified, experts representing them can be invited to serve as the epistemic base for further research.

\subsection{Explication of the four phases}

\subsubsection{Developing the understanding of the problem situation}

Developing the researcher's understanding of the problem situation is a prerequisite for identifying important actors. Unfortunately, research into problem situations often begins with little knowledge of the issue under study. Moreover, in many cases, there is no scientific literature available that adequately addresses the specifics of the problem situation, or else the literature provides only partial insights. In societal problem situations, there may be no written information available, and it is unlikely that a single person could guide the researchers because, in fragmented situations, no single person has a sufficiently broad perspective on the important actors. This contrasts with research conducted in an organizational context. In such a context, an experienced practitioner can often serve as a gatekeeper who provides researchers with a list of potential experts and written information that can inform the researchers in the initial phases of the project.

Researchers in the initial phase of a project rely on everyday knowledge or must make assumptions concerning the problem situation. In some cases, the initial understanding of the problem situation may seem so trivial that it is not even recognized as a distinct phase, and phase 2 or even phase 3 may appear to be the starting point of the research process.

To overcome the initial lack of knowledge, any available source of information, from the researcher's everyday knowledge and information found on the Internet to information derived from participants, can be used to develop the understanding of the problem situation. A lack of confidence in accuracy poses no problem at this early stage of the research process because testing and subsequent adaptation are constitutive elements of the method. The distortions and weaknesses of the researchers' early understanding of the problem situation will be overcome during the subsequent research process.

Depending on the requirements of the research project and the working style of the researchers, the insights gained in the first phase can principally remain in the researcher's "mental data base" (Forrester, 1987), be expressed as written text, be put into a computer database, or structured in any way, such as using one of the problem structuring methods reported in Rosenhead and Mingers (2001) or by developing formal models.

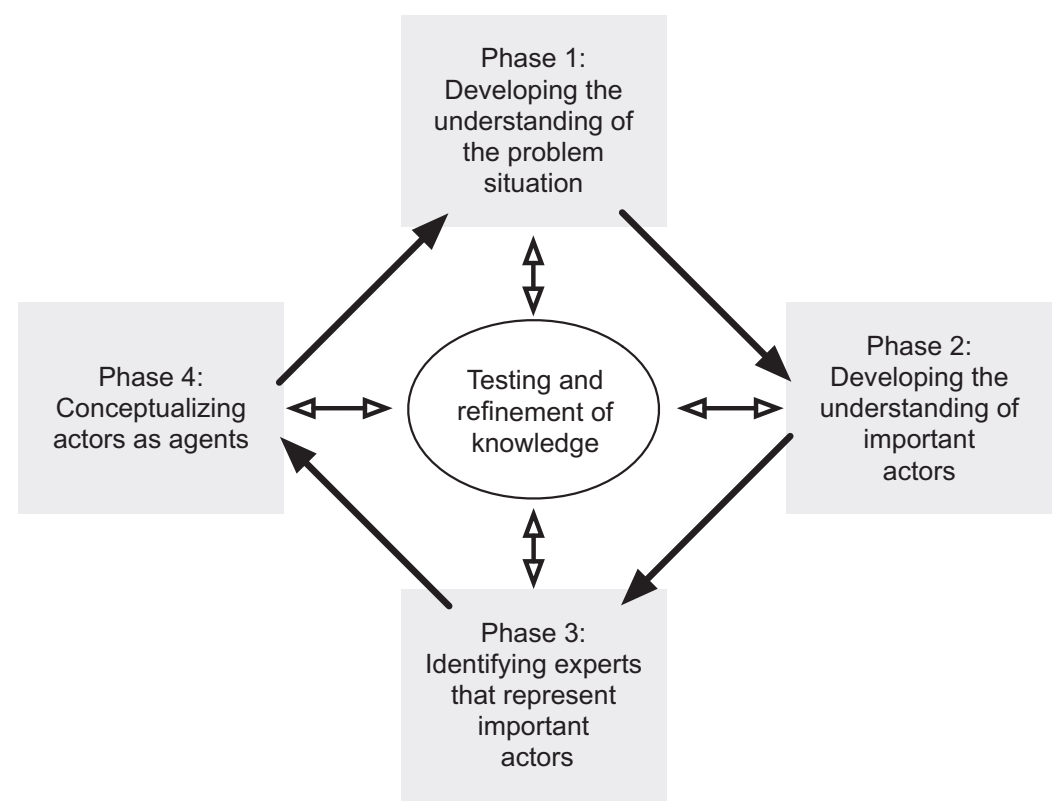

Fig. 1. Overview of the method. 


\subsubsection{Developing the understanding of important actors}

Informed guesses regarding which actors might drive the societal problem situation are only the starting point. Investigating the empirical manifestations of the problem situation through activities such as searching the Internet, reviewing literature, talking to or interviewing people participating in the situation, or analyzing numerical data increases the overall understanding of the situation and its actors. Repeated questioning, testing, verifying, cross-referencing and adapting the knowledge gained leads to the emergence of an increasingly valid and accurate understanding of the important actors.

At this point, the question emerges of how to distinguish between important and unimportant actors. However, this question must be answered in the specific context of projects. We refer to the literature on stakeholder management (see for example Achterkamp and Vos, 2007; Bryson, 2004; Bryson et al., 2004; Ackermann and Eden, 2011; Eden and Ackermann, 1998; Mitchell et al., 1997) rather than proposing substantive criteria according to which actors might be identified as important.

\subsubsection{Identification of experts that represent important actors}

The main task to be accomplished in this step is to identify and contact persons who are able and willing to represent the perspectives of important actors in the research. Representatives are required because collaborative research relies on working with real persons and it is generally not possible to collaborate with collective actors or categories of actors such as "consumers" or a whole corporation. Finding representatives may be straightforward or nearly impossible, depending on the specifics of the situation under study.

It may prove helpful to ask the experts already contacted who they would include and to then contact the persons suggested by the experts. By going from one expert to another, a list of potentially relevant actors and individuals, who might be considered as experts, can be compiled. While this approach promises to be effective, it runs the risk of identifying experts within a specific network and not representing important actors from other, possibly competing networks. Therefore, great care must be taken to access other, possibly competing networks to obtain a variety of represented perspectives. Additionally, it may prove important to ensure that experts are drawn from a variety of backgrounds, as the social background of an expert may intersect with his or her perception of the actor's perspective on the problem situation. This can help reduce bias stemming from background variables, such as gender, ethnicity, age, and hierarchical position.

\subsubsection{Conceptualizing actors as agents}

Agents are ideal-typical representations of actors that condense the relevant aspects of the real world as a result of a process of methodical inquiry. Depending on the specifics of the research project, it may suffice to simply define agents according to their relevant functions. In many cases, however, an elaboration of the behavior patterns and decision functions of agents is required. The conceptualization of agents involves endeavors such as cross-referencing, merging and testing the insights derived from collaborating with experts.

Ideally, several experts familiar with the perspective of an actor would be interviewed or consulted. However, the variety of perspectives considered is more important than the actual number of experts consulted. Subsequently, researchers can develop a 'dense description' or a more formal model capturing the central interests, values and actions carried out by each actor or category of actors identified as important.

Based on these empirically well-founded "dense descriptions" of important actors, the research team can return to phase 1 to refine and update its understanding of the system. To ensure that the researchers' understanding of the problem situation is represented in an intersubjectively valid model, group-oriented methods such as workshops, focus groups or group model building can be employed. Together with the expert group, the researchers can test and refine their understanding of the societal problem situation, identify missing actors and refine the conceptualization of agents.

\section{Conclusions}

Finding experts who represent important actors is not an end in itself. Rather, it is a necessary precondition to conduct collaborative research, regardless of the specific methodology used. In the context of a research project, we combined methods from strategic management, operational research and systems thinking to analyze the diffusion of energy-efficient buildings. However, we failed to find a terminology that deals in general with acting entities in societal problem situations and transcends the specifics of the different methods we used. In addition, we failed to find an approach in the literature that would provide us with specific guidance on how to identify and select representatives of important actors in societal problem situations. In the sections above, we proposed terminology and a process to identify and select experts representing important actors or categories of actors in societal problem situations. In addition, we provided the theoretical foundations underlying our approach, and, by way of example, we evaluated the potential benefits of our approach. The research questions we stated in the introduction were answered as follows. We addressed research question 1 by elaborating on the characteristics of societal problem situations in Section 3.2. We addressed research question 2 by providing a conceptualization of acting entities in Section 3.1. We addressed research question 3 by proposing a method to identify capable individuals in Section 4 and provide a case study of its application in an electronic supplement to this article.

The added value of applying our approach in collaborative research is that the selection of individuals to represent important actors becomes a distinct, reflective and important phase of the research process rather than a preliminary administrative task. In organizational contexts, it may be the case that gatekeepers do a good job of selecting experts who represent important actors or categories of actors. In the context of collaborative research into societal problem situations, however, gatekeepers might be hard pressed to provide a valid account of important actors or categories of actors and experts representing them. In such situations, we expect our method to yield a group of experts who represent the important actors of a societal problem situation, and we expect our method to be more advantageous in comparison to ad hoc approaches that rely on the perspective of an individual gatekeeper. Consequently, we expect collaborative research projects to produce better insights.

We propose our method and the terminology that grounds it as a plug-in for collaborative research approaches in stakeholder theory, System Dynamics and problem structuring methods. In the context of (collaborative) problem structuring methods, we find that our method can be easily integrated by applying it as a first step. Systematically researching which actors or categories of actors need to be considered in the societal problem situation is already a step toward structuring a societal problem situation and, in our opinion, should be treated as such. The identification of individuals capable of representing actors or categories of actors is then a prerequisite for applying further techniques from soft OR. We do not think that our contribution is directly applicable to stakeholder theory; however, our distinction between actors, experts and agents may yield some ontological clarity in that context. A stakeholder can be defined as an individual or collective actor or a category of actors who can affect, or is affected by, the 
achievement of an organization's objectives. Experts are individuals capable of representing the perspective of stakeholders. In collaboration with experts, agents representing stakeholders can be conceptualized and used to methodologically investigate stakeholder management strategies. By offering the possibility to refer to agency in inter-organizational contexts, we contribute to keeping the stakeholder term focused on its original organizational perspective. To identify the stakeholders of a specific organization, our approach is probably of limited value. In such a situation, classification schemes and techniques, such as those discussed by Bryson (2004), are probably more adequate. In System Dynamics, however, our method and terminology should be useful; we provide a terminology to deal with agency in social systems and a method to assemble a group of system experts who represent the important actors in such systems.

While we hope to have contributed clear terminology and a useful method, we must emphasize that the method we have presented is conceptual rather than strictly prescriptive, as each collaborative research project faces unique challenges that may require adaptations. Therefore, we see our contribution as being in line with the spirit of multi-method approaches (Mingers and Brocklesby, 1997). Hence, it seems probable that the proposed method will need to be adapted to the specifics of different research projects.

While we are confident that we did not miss out any substantial contributions elaborating on the identification and selection of experts in the reviewed literature, we were unable to conduct a broad and systematic analysis of the literature reporting cases of collaborative research. The task of systematically analyzing such contributions remains an object for further research. Such an enterprise could provide a typology of approaches taken regarding the identification and selection of actors and highlight the specific benefits of the identified approaches.

\section{Acknowledgements}

The authors thank Ruth Kaufmann-Hayoz, Franz Schultheis, Markus Schwaninger and Alexander Wokaun for their continued support of their research. The authors thank the three anonymous reviewers, Susanne Bruppacher, Antonietta di Giulio, Ruth Kaufmann-Hayoz and Andrea Mordasini for very helpful comments towards improving this article. This research was supported by the Swiss National Science Foundation within the context of the national research program 54 (sustainable development of the built environment), Novatlantis - Sustainability at the ETH domain, the Swiss Federal Office of Energy, the City of Zürich, the Interdisciplinary Centre for General Ecology (IKAÖ, at University of Bern) and Paul Scherer Institut.

\section{Appendix A. Supplementary data}

Supplementary data associated with this article can be found, in the online version, at doi:10.1016/j.ejor.2011.07.014.

\section{References}

Achterkamp, M.C., Vos, J.F.J., 2007. Critically identifying stakeholders. Evaluating boundary critique as a vehicle for stakeholder identification. Systems Research and Behavioural Science 24, 3-14.

Ackermann, F., Eden, C., 2001. SODA - Journey making and mapping in practice. In: Rosenhead, J., Mingers, J. (Eds.), Rational analysis for a problematic world revisited, Problem Structuring Methods for Complexity, Uncertainty and Conflict. John Wiley \& Sons, Chichester, pp. 21-42.

Ackermann, F., Eden, C., 2011. Strategic management of stakeholders: Theory and practice. Long Range Planning 44, 179-196.

Ackoff, R.L., 1979. The future of operational research is past. Journal of the Operational Research Society 30, 93-104.
Ackoff, R.L., 1999. Re-creating the Corporation: A Design of Organizations for the 21st Century. Oxford University Press, New York.

Andersen, D., Richardson, G., 1997. Scripts for group model building. System Dynamics Review 13 (2), 107-129.

Andersen, D., Richardson, G., Vennix, J., 1997. Group model building: Adding more science to the craft. System Dynamics Review 13 (2), 187-201.

Beer, S., 1984. The viable system model: Its provenance, development, methodology and pathology. Journal of the Operational Research Society 35 (1), 7-25.

Bennet, P., Bryant, J., Howard, N., 2001. Drama theory and confrontation analysis. In: Rosenhead, J., Mingers, J. (Eds.), Rational Analysis for a Problematic World Revisited, Problem Structuring Methods for Complexity, Uncertainty and Conflict. John Wiley \& Sons, Chichester, pp. 225-248.

Blumer, H., 1971. Social problems as collective behavior. Social Problems 18 (3), 298-306.

Bryson, J.M., Ackermann, F., Eden, C., Finn, C.B., 2004. Visible Thinking. Unlocking Causal Mapping for Practical Business Results. John Wiley \& Sons, Chichester.

Bryson, J.M., 2004. What to do when stakeholders matter: Stakeholder identification and analysis techniques. Public Management Review 6 (1), 21-53.

Checkland, P., 1993. Systems Thinking, Systems Practice. John Wiley \& Sons, Chichester.

Checkland, P., Scholes, J., 1990. Soft Systems Methodology in Action. John Wiley \& Sons, Chichester.

Checkland, P., 2001. Soft systems methodology. In: Rosenhead, J., Mingers, J. (Eds.), Rational Analysis for a Problematic World Revisited, Problem Structuring Methods for Complexity, Uncertainty and Conflict. John Wiley \& Sons, Chichester, pp. 61-90.

Donaldson, T., Preston, L.E., 1995. The stakeholder theory of the corporation: Concepts, evidence and implication. Academy of Management Review 20 (1), $65-91$.

Eden, C., Ackermann, F., 1998. Making strategy. The Journey of Strategic Management. SAGE Publications, London.

Eden, C., 1996. The stakeholder/collaborator strategy workshop. In: Huxham, C. (Ed.), Collaborative Advantage. Sage, London, pp. 44-56.

Flick, U., 2005. Qualitative Sozialforschung. Rowohlts Enzyklopädie, Reinbek bei Hamburg.

Franco, L.A., 2009. Problem structuring methods as intervention tools: Reflections from their use with multi-organisational teams. Omega 37, 193-203.

Freeman, E.R., 1984. Strategic Management. A Stakeholder Approach. Pitman Publishing, Marshfield (MA).

Friedman, A., Miles, S., 2006. Stakeholders. Theory and Practice. Oxford University Press, Oxford.

Friend, J., 1990. Handling organizational complexity in group decision support. In: Eden, C., Radford, J. (Eds.), Tackling Strategic Problems: The Role of Group Decision Support. Sage, London, pp. 18-28.

Forrester, W.J., 1987. Lessons from system dynamics modeling. System Dynamics Review 3 (2), 136-149.

Gadamer, H.G., 1975. Hermeneutics and social science. Philosophy \& Social Criticism 2 (4), 307-316.

Glaser, B., Strauss, A., 1967. The Discovery of Grounded Theory: Strategies for Qualitative Research. Aldine De Gruyter, New York.

Hermans, L.M., Thissen, W.A.H., 2009. Actor analysis methods and their use for public policy analysts. European Journal of Operational Research 196, 808-818.

Kitsuse, J., Spector, M., 1973. Toward a sociology of social problems: Social conditions, value-judgements, and social problems. Social Problems 20 (4), 407-419.

Mingers, J., Brocklesby, J., 1997. Multimethodology: Towards a framework for mixing methodologies. Omega, International Journal of Management Science 25 (5), 489-509.

Mingers, J., Rosenhead, J., 2004. Problem structuring methods in action. European Journal of Operational Research 152, 530-554.

Mitchell, R., Agle, B., Wood, D., 1997. Toward a theory of stakeholder identification and salience: Defining the principle of who and what really counts. Academy of Management Review 22 (4), 853-886.

Pohl, C., 2008. From science to policy through transdisciplinary research. Environmental Science and Policy 11 (1), 46-53.

Reason, P., Bradbury, H. (Eds.), 2001. Handbook of Action Research: Participatory Inquiry and Practice. Sage Publications, London, Thousand Oaks, New Delhi.

Rittel, H.W.J., Webber, M.M., 1973. Dilemmas in a general theory of planning. Policy Science 4, 155-169.

Robinson, J., Tansey, J., 2006. Co-production, emergent properties and strong interactive social research: The Georgia Basin Futures Project. Science and Public Policy 33, 151-160.

Rosenhead, J., 2001a. Preface. In: Rosenhead, J., Mingers, J. (Eds.), Rational Analysis for a Problematic World Revisited, Problem Structuring Methods for Complexity, Uncertainty and Conflict. John Wiley \& Sons, Chichester, pp. xiiixvi.

Rosenhead, J., 2001b. Robustness analysis: Keeping your options open. In: Rosenhead, J., Mingers, J. (Eds.), Rational Analysis for a Problematic World Revisited, Problem Structuring Methods for Complexity, Uncertainty and Conflict. John Wiley \& Sons, Chichester, pp. 181-207.

Rosenhead, J., Mingers, J. (Eds.), 2001. Rational Analysis for a Problematic World Revisited. Problem Structuring Methods for Complexity, Uncertainty and Conflict. John Wiley \& Sons, Chichester.

Savage, G.T., Nix, T.W., Whitehead, C.J., Blair, J.D., 1991. Strategies for assessing and managing organizational stakeholders. Academy of Management Executive 5 (2), 61-75. 
Schön, D.A., 1983. The Reflective Practitioner: How Professionals Think in Action. Basic Books, New York.

Schön, D.A., 1987. Educating the Reflective Practitioner: Towards a New Design for Teaching and Learning in the Professions. Jossey-Bass, San Francisco.

Scholz, R.W., Mieg, H.A., Oswald, J.E., 2000. Transdisciplinarity in groundwater management - Towards mutual learning of science and society. Water, Air, and Soil Pollution 123, 477-487.

Schwaninger, M., 2009. Intelligent Organizations. Powerful Models for Systemic Management. Springer, Berlin, Heidelberg, New York.

Schwaninger, M., 2004. Methodologies in conflict: Achieving synergies between system dynamics and organizational cybernetics. Systems Research and Behavioral Science 21, 411-431.

Strübing, J., 2004. Grounded Theory. Zur sozialtheoretischen und epistemologischen Fundierung des Verfahrens der empirisch begründeten Theoriebildung. VS Verlag für Sozialwissenschaften, Wiesbaden.

Thompson Klein, J., Grossenbacher-Mansuy, W., Haeberli, R., Bill, A., Scholz, R.W., Welti, M., 2001. Transdisciplinarity: Joint Problem Solving Among Science,
Technology, and Society: An Effective Way for Managing Complexity. Birkhäuser, Basel.

Vennix, J., 1996. Group Model Building: Facilitating Team Learning Using System Dynamics. John Wiley \& Sons, New York.

Vennix, J., 1999. Group model building: Tackling messy problems. System Dynamics Review 15 (4), 379-401.

Weinberg, D., 2009. On the social construction of social problems and social problems theory: A contribution to the legacy of John Kitsuse. The American Sociologist 40 (1-2), 61-78.

White, L., Lee, G.J., 2009. Operational research and sustainable development: Tackling the social dimension. European Journal of Operational Research 193, 683-692.

Wiek, A., 2007. Challenges of transdisciplinary research as interactive knowledge generation - Experiences from transdisciplinary case study research. GAIA Ecological Perspectives for Science and Society 16, 52-57.

Wiek, A., Walter, A.I., 2008. A transdisciplinary approach for formalized integrated planning and decision-making in complex systems. European Journal of Operational Research 197 (1), 360-370. 